Editorial

\title{
Teaching 2.0: What's Growth Mindset and Psychological Safety Got to Do with It?
}

\author{
Nisha Chadha, $\mathrm{MD}^{10}$ \\ ${ }^{1}$ Department of Ophthalmology, Icahn School of Medicine at Mount \\ Sinai/New York Eye and Ear, Eye and Vision Research Institute, \\ New York, New York
}

J Acad Ophthalmol 2020;12:e20-e21.

"Do you offer femtosecond cataract surgery? MIGS? The Yamane technique? miLoop?" And the list of training experience-related questions we've all encountered from prospective trainees goes on. These are all valid inquiries when one of the allures of our field is, after all, the fascinating microsurgical aspects. Ophthalmology and medicine are experiencing an exciting time of technological and surgical advancement, but what are the implications for our trainees and educators? Educators are faced with the challenge of not only keeping current with these advancements, but also incorporating new technology into the curriculum.

While our efforts to update curricula are necessary and laudable, the truth is, there will be continued advancements and we can't possibly teach our trainees everything before they graduate. So, how do we address this challenge and potential knowledge gap? As a young attending, I've found that continued learning without the structure of a training program is challenging, and I wonder how we might make this process easier for our future physicians. I believe a first step toward maintaining excellent, up-to-date care for our patients is instilling values of self-directed learning and reflection in our trainees. ${ }^{1,2}$ However, doing so requires that we as educators embody these values and model them ourselves. So, how do we do this?

"But that's what the attending wants." This is a comment many of us may have uttered or thought as a trainee, when considering the optimal management for a patient. Perhaps a resident may have considered a DSAEK as the best option, when the attending is offering a penetrating keratoplasty, but doesn't speak up, fearing how it may be perceived. Or perhaps a trabeculectomy is planned and the resident is concerned with the patient's ability to follow-up, but does not think that this information will change the attending's approach, and therefore doesn't raise it. Medicine demands complex problem solving and what better way to approach such situations than with teamwork? Yet, while teamwork is encouraged, the hierarchal nature of our teams often inhibits the shared thinking and creative potential that working together offers. The high stakes nature of medicine has not allowed any room for failure, mistakes, or uncertainty. But, if we don't acknowledge and reflect on our failures or invite alternate thought, we can't grow or be open to feedback. In psychology, this is referred to as "growth mindset" versus "fixed mindset." 3 A growth mindset approaches failure as an opportunity to learn and improve, whereas a fixed mindset views failure as an individual shortcoming that cannot be overcome, and often leads to feelings of shame, which can inhibit further learning. ${ }^{3,4}$

If we share our failures with our trainees, we can destigmatize their occurrence, which is inevitable, and model a growth mindset approach, to learn from failure. And if we don't, we take the risk of allowing our trainees to become stuck in a fixed mindset. How can our trainees develop a growth mindset if they aren't aware of its power ${ }^{5}$ In sharing not only expertise, but also failure with our trainees, we can model life-long learning and narrow the distance created by hierarchy to encourage bidirectional learning. In doing so, we create an environment of psychological safety, a quality which expert and author Amy Edmondson considers the "extra ingredient" for organizational success. ${ }^{6}$ Psychological safety is defined as "being able to show and employ one's self without fear of negative consequences of self-image, status, or career." ${ }^{7}$ Specifically in our profession, it describes "how a learning environment mitigates or exacerbates the risks learners must take to learn medicine." 8 There's ample data demonstrating the positive effect of psychological safety on performance and success of teams and organizations. Consider a mainstream example, Project Aristotle, a study conducted to determine the key attributes of high-performing teams at Google, which found psychological safety to be, "far and away the most important of five (team) dynamics," identified. ${ }^{9}$
Address for correspondence Nisha Chadha, MD, Department of Ophthalmology, Icahn School of Medicine at Mount Sinai, 17

East 102nd Street, 8th Floor West, New York, NY 10029

(e-mail: Nisha.chadha@mssm.edu).
DOI https://doi.org/ 10.1055/s-0040-1703017. ISSN 2475-4757.
Copyright @ $\odot 2020$ by Thieme Medical Publishers, Inc., 333 Seventh Avenue, New York, NY 10001, USA. Tel: +1(212) 760-0888.

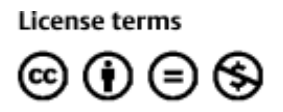




In creating an environment of psychological safety, our trainees will feel more comfortable discussing concerns, sharing alternate thoughts on patient care, and reporting failures, and ultimately our patients will benefit. I'm sure many of us role model reflection and growth mindset, and inspire psychologically safe environments already, but being aware of their significance and explicitly discussing their importance with our teams and trainees are essential to sustaining their practice.

"I don't know" is another dreaded phrase in medicine which is often met with criticism, creating embarrassment. In a psychologically safe environment, perhaps this response can be met more supportively, not necessarily with the answer, but with further inquiry to clarify learning needs, rather than with humiliation. ${ }^{10}$ In doing so, the moment can be transformed into an "intelligent failure." ${ }^{16}$ An environment of psychological safety facilitates a growth mindset and reflection, leverages the strengths of teamwork, facilitates bidirectional learning and feedback, and inspires self-directed and life-long learning. Sounds ideal, right? Unlike other systemic challenges we face in medicine, I think this one is readily achievable. It starts with recognizing the power of psychologically safe environments on our trainees, ourselves, and our patients, and then cultivating it with our learners. This way of thinking is intrinsically positive, and there may be downstream benefits, including decreased burnout and improved wellness. ${ }^{2,11,12}$ Studies have shown resident satisfaction with the learning environment and program evaluations were strongly correlated with level of psychologically safety experience. ${ }^{13,14}$ With the innovation overload we are facing, we need educational strategy, now more than ever, and inspiring a growth mindset and a psychologically safe learning environment, is key.

"Will this experience can prepare you for higher level lifelong learning?," I think when asked about training experiences at our institution. "Higher level" means learning from each experience, whether clinical or surgical, through selfreflection, self-directed learning, teamwork, and mentorship. If we maximize every experience, cognitively and professionally, the benefits surpass that which is quantified in a case log. Better than signing off on a trainee who is achieving minimums, wouldn't it be nice to sign diplomas of metacognitive graduates, graduates who are able to assess their strengths and weaknesses accurately, and identify and fulfill their learning needs? I'm challenging myself to this "higher level" by striving to model of a growth mindset and build a greater environment of psychological safety, and I hope you will join me. I may fail, but hopefully with a growth mindset, I will "stumble upward." 15 I'm excited for a future where attendinghood is not viewed as the end of professional development, but simply the next rung on the ladder of maximizing one's potential, and learning is truly lifelong.

Conflict of Interest

None declared.

\section{References}

1 Knowles M. Self-Directed Learning: A Guide for Learners and Teachers. New York, NY: Association Press; 1975

2 Guglielmino LM. The case of promoting self-directed learning in formal educational institutions. SA-Educ Journal 2013;10(02): 1-18

3 Dweck CS. Mindset: The New Psychology of Success. New York, NY: Penguin Random House; 2006

4 Lindsay-Hartz J. Contrasting experiences of shame and guilt. Am Behav Sci 1984;27(06):689-704

5 Klein J, Delany C, Fischer MD, Smallwood D, Trumble S. A growth mindset approach to preparing trainees for medical error. BMJ Qual Saf 2017;26(09):771-774

6 Edmondson AC. The Fearless Organization: Creating Psychological Safety in the Workplace for Learning, Innovation, and Growth. Hoboken, NJ: John Wiley and Sons, Inc.; 2019

7 Kahn WA. Psychological conditions of personal engagement and disengagement a work. Acad Manage J 1990;33(04):692-724

8 Bynum WE, Haque TM. Risky business: psychological safety and the risks of learning in medicine. J Grad Med Educ 2016;8(05): 780-782

9 Rozovsky J. The five keys to a successful Google team. Available at: https://rework.withgoogle.com/blog/five-keys-to-a-successfulgoogle-team/. Accessed July 15, 2019

10 Kusurkar RA, Croiset G, Ten Cate TJ. Twelve tips to stimulate intrinsic motivation in students through autonomy-supportive classroom teaching derived from self-determination theory. Med Teach 2011;33(12):978-982

11 Ding M, Babenko O, Koppula S, Oswald A, White J. Physicians as Teachers and Lifelong Learners. J Contin Educ Health Prof 2019;39 (01):2-6

12 Swendiman RA, Edmondson AC, Mahmoud NN. Burnout in surgery viewed through the lens of psychological safety. Ann Surg 2019;269(02):234-235

13 Torralba KD, Loo LK, Byrne JM, et al. Does psychological safety impact the clinical learning environment for resident physicians? Results from the VA's learners' perceptions survey. J Grad Med Educ 2016;8(05):699-707

14 Appelbaum NP, Santen SA, Aboff BM, Vega R, Munoz JL, Hemphill RR. Psychological safety and support: assessing resident perceptions of the clinical learning environment. J Grad Med Educ 2018; 10(06):651-656

15 Chugh D. The Person You Mean to Be. New York, NY: HarperCollins Publishers; 2018 